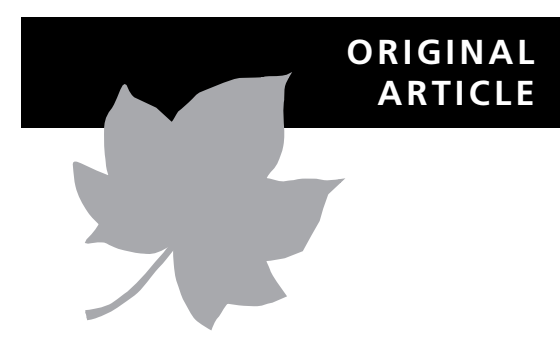

\title{
Phylogeography and polyploid evolution of North American goldenrods (Solidago subsect. Humiles, Asteraceae)
}

\author{
Jess A. Peirson ${ }^{1,2 \star}$, Christopher W. Dick ${ }^{1,2}$ and Anton A. Reznicek ${ }^{2}$
}

${ }^{1}$ Department of Ecology and Evolutionary Biology, University of Michigan, Ann Arbor, Michigan, USA, ${ }^{2}$ University of Michigan Herbarium, Ann Arbor, Michigan, USA
${ }^{\star}$ Correspondence: Jess A. Peirson, Department of Ecology and Evolutionary Biology, University of Michigan, 830 North University, Ann Arbor, MI 48109-1048, USA. E-mail: peirsonj@umich.edu

\section{ABSTRACT}

Aim We analysed range-wide chloroplast DNA (cpDNA) variation in a clade of North American goldenrods (Solidago subsect. Humiles) to infer its biogeographical history and evolution. Our objectives were to: (1) examine the structuring of cpDNA diversity in this widespread species complex, (2) reconstruct Pleistocene refugia and post-glacial migration of the study species, and (3) test hypotheses relating to the frequency of polyploidization. We expected the glacial history of Solidago to differ markedly from that of temperate trees and forest understorey plants.

Location North America (Canada, continental USA, Mexico).

Methods $1466 \mathrm{bp}$ of chloroplast intergenic spacer DNA (cpDNA) were sequenced from 368 individuals representing 72 populations of subsect. Humiles, which consists of the widespread Solidago simplex and four geographically restricted species. Estimates of $N_{\mathrm{ST}}$ and $G_{\mathrm{ST}}$ were compared as a test of phylogeographical structure, and spatial analysis of molecular variance (SAMOVA) was used to examine cpDNA variation. Rarified haplotype diversity and chromosome diversity (ploidy levels) were used to infer locations of glacial refugia and post-glacial expansion, and to determine origins of polyploidy, respectively.

Results A total of 46 haplotypes were recovered. While there was significant phylogeographical structure $\left(N_{\mathrm{ST}}>G_{\mathrm{ST}}\right)$, cpDNA variation was not strongly partitioned across species boundaries, geography or ploidy levels, and six haplotypes were shared among species. The highest haplotype diversity was located in western North America, followed by the south-eastern USA and the formerly glaciated Great Lakes region.

Main conclusions Solidago simplex recolonized formerly glaciated eastern North America from refugia in western North America and near the perimeter of the ice margin. The south-eastern USA had only limited involvement in recolonization of these northern regions. The geographical disjunction and scattered positions of polyploids in the haplotype network provide evidence of multiple polyploid origins within S. simplex, and the restriction of endemic, polyploid taxa to post-glacial habitats provides evidence of Holocene polyploid speciation. The results highlight polyploidization as a source of adaptive genetic variation and speciation in novel and post-glacial habitats.

\section{Keywords}

Chloroplast DNA, goldenrods, haplotype sharing, Holocene biogeography, North America, phylogeography, polyploidy, post-glacial migration, Solidago. 


\section{INTRODUCTION}

Quaternary climatic oscillations caused pronounced changes in species distributions and altered the genetic structure of populations across the Northern Hemisphere (Hewitt, 2000, 2003). The classical view of Northern Hemisphere Quaternary biogeography posits that repeated continental glaciations caused poleward shifts in species ranges and isolated populations in primarily southern refugia (Davis, 1983; Bennett et al., 1991; Latham \& Ricklefs, 1993; Williams et al., 2000). During interglacial periods, many species rapidly expanded their ranges northwards. Repeated cycles of southward range contraction and northward expansion produced a genetic signature of 'southern richness' and 'northern purity' in many species (following Hewitt, 1996, 1999). Phylogeographical studies have demonstrated the importance of southern glacial refugia for many temperate trees and forest understorey plants (reviewed in Taberlet et al., 1998; Soltis et al., 2006). Recent studies of widespread and northern temperate and boreal plants, however, have revived early hypotheses (e.g. Braun, 1928; Marie-Victorin, 1938) that some species survived the Last Glacial Maximum (21-18 ka) in northern refugia nearer the ice margin (Stewart \& Lister, 2001; Rowe et al., 2004; McLachlan et al., 2005; Shafer et al., 2010). Phylogeographical data have also revealed evidence of admixture of haplotypes from multiple glacial refugia (Petit et al., 2003; van Els et al., 2012) and interspecific hybridization (Saeki et al., 2011) at higher latitudes for some species, resulting in greater diversity in nonrefugial areas. These cumulative data indicate that many species responded idiosyncratically to Quaternary climatic changes (Prentice, 1986; Huntley \& Webb, 1989; Stewart et al., 2010).

Solidago L. subsect. Humiles (Rydb.) Semple (Asteraceae) presents an interesting system in which to examine Quaternary biogeography and diversification across North America. The subsection has one widespread, morphologically and cytologically variable species, Solidago simplex Kunth, and four geographically restricted species: Solidago arenicola Keener \& Kral, Solidago kralii Semple, Solidago plumosa Small and Solidago spathulata DC. It is endemic to North America and occupies four disjunct centres of distribution (Fig. 1). There is significant cytogeographical structuring within the subsection, and diploid and polyploid cytotypes co-occur regionally in the south-eastern United States and in formerly glaciated areas of eastern North America. This distribution of cytotypes has been proposed as evidence that polyploids evolved multiple times (Peirson et al., 2012).

Investigation of widespread, generally non-forest herbs such as Solidago has the potential to uncover Pleistocene and Holocene biogeographical histories that may be shared by many other elements of the North American flora. Many previous phylogeographical studies in North America have emphasized major biome components such as forest trees (see summary and review in Jaramillo-Correa et al., 2009) and forest understorey plants that, although ecologically important, comprise specialized components of the flora. Because goldenrods are perennial herbs with wind dispersed seeds, their life-history traits and dispersal capabilities certainly differ from those of large-seeded, long-lived forest trees. Therefore, we expect that their responses to Quaternary climatic changes probably differed as well.

We analysed range-wide chloroplast genetic diversity in Solidago subsect. Humiles in order to: (1) examine the structuring of chloroplast DNA (cpDNA) diversity with regard to species boundaries, geography and ploidy levels in this widespread North American species complex, (2) reconstruct Pleistocene refugia and post-glacial migration of the study species, and (3) test hypotheses relating to the frequency of polyploidization.

\section{MATERIALS AND METHODS}

\section{Study system}

Goldenrods in Solidago subsect. Humiles have resinous glands on the foliage and involucral bracts such that all members are sticky to the touch, a unique characteristic in the genus of c. 100 species (Semple \& Cook, 2006). Members of S. subsect. Humiles generally occur in non-forest habitats and are not weeds.

Solidago arenicola is restricted to rocky or sandy riverbanks and floodplains in the Cumberland Plateau region of northern Alabama and Tennessee (Table 1). Of the four narrowly distributed species, it is the only polyploid. Solidago kralii is confined to sand hills along the Coastal Plain fall line in Georgia and South Carolina. Solidago plumosa is known from a single population on mafic rocks along the Yadkin River in Stanley Co., North Carolina. Solidago spathulata inhabits sand dunes along the Pacific Coast from central California to northern Oregon (Table 1). Solidago simplex is divided into diploid S. simplex subsp. simplex and polyploid S. simplex subsp. randii. Diploid subspecies simplex is widespread in montane and alpine habitats throughout the western cordillera from Alaska to Mexico (Fig. 1). Disjunct eastern diploids in the northern Great Lakes region and Gaspé, Quebec, have also been placed in subspecies simplex (Fig. 1). Polyploid subspecies randii is restricted to the Great Lakes region and Appalachian Mountains in eastern North America (Fig. 1). Four varieties are currently recognized in subspecies randii, with two of those endemic to the formerly glaciated Great Lakes region (Table 1).

\section{Taxon and population sampling}

A total of 368 accessions of Solidago subsect. Humiles from 72 populations (including 289 individuals from 57 populations of S. simplex) were collected from throughout North America (locality, sampling and voucher details are presented in Appendix S1 in Supporting Information). Sampling included all species within $S$. subsect. Humiles and all 


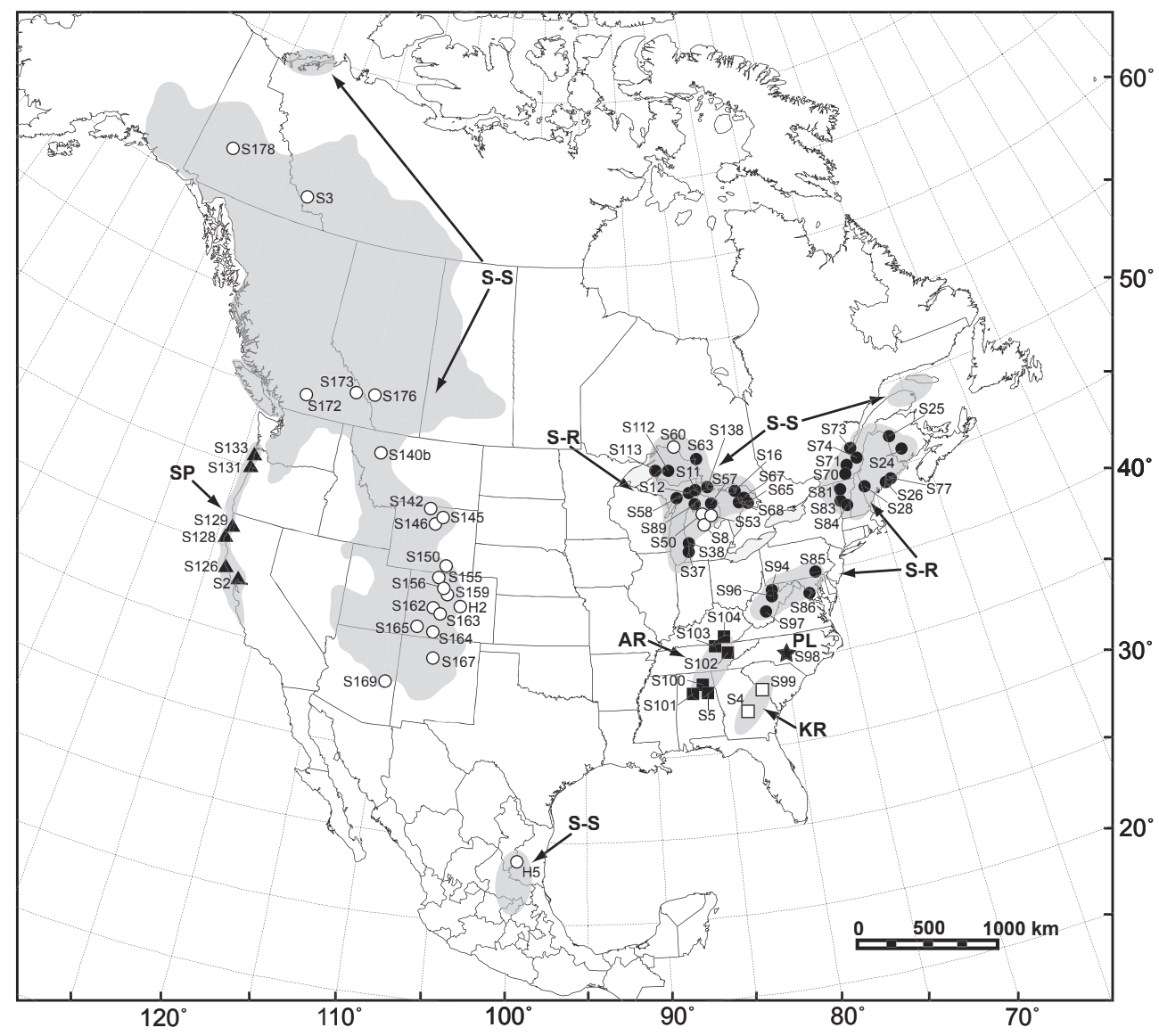

Figure 1 Distribution of Solidago subsect. Humiles in North America. Generalized taxon distributions are indicated by grey shading except for S. plumosa, which is indicated by a single star: S. arenicola (AR), S. kralii (KR), S. plumosa (PL), S. simplex subsp. randii (S-R), S. simplex subsp. simplex (S-S), S. spathulata (SP). Sampling localities for this study are as follows: S. arenicola (closed squares), S. kralii (open squares), S. plumosa (star), S. simplex subsp. randii (closed circles), S. simplex subsp. simplex (open circles), and S. spathulata (triangles). The Great Lakes region is the only area where taxon distributions overlap.

Table 1 Summary of natural history information for Solidago subsect. Humiles. Ploidy data are summarized from Peirson et al. (2012). Geographical distributions are as follows: western North America (WNA), Great Lakes Region (GR), north-eastern North America (NE), and south-eastern United States and Southern Appalachians (SEUS). Solidago simplex is the only species in the subsection with recognized infraspecific taxa.

\begin{tabular}{|c|c|c|c|}
\hline Taxon & Ploidy & Geography & Habitat \\
\hline S. arenicola & $4 x$ & SEUS & Gravel/sand riverbanks of the Cumberland Plateau \\
\hline S. kralii & $2 x$ & SEUS & Pinelands and xeric sand hills along the SEUS Coastal Plain fall line \\
\hline S. plumosa & $2 x$ & SEUS & Rock riverbanks along the Yadkin River \\
\hline S. simplex & $2 x, 4 x, 6 x$ & WNA, GL, NE & - \\
\hline subsp. simplex & $2 x$ & WNA, GL, NE & - \\
\hline var. chlorolepis & $2 x$ & $\mathrm{NE}$ & Rock barrens and uplands of the Gaspé Peninsula \\
\hline var. nana & $2 x$ & WNA & Alpine habitats in the Cascade Mountains \\
\hline var. simplex & $2 x$ & WNA, GL & Rock/sand/alpine habitats in western N. America and disjunct to the Great Lakes Region \\
\hline subsp. randii & $4 x, 6 x$ & GL, NE, SEUS & - \\
\hline var. gillmanii & $4 x$ & GL & Coastal sand dunes of Lake Huron and Lake Michigan \\
\hline var. ontarioensis & $4 x$ & GL & Rock lakeshores of Lake Huron, Lake Michigan and Lake Superior \\
\hline var. monticola & $4 x$ & $\mathrm{NE}$ & Rock uplands in New England and Quebec \\
\hline var. racemosa & $4 x, 6 x$ & NE, SEUS & Rock riverbanks throughout the Appalachian Mountains \\
\hline S. spathulata & $2 x$ & WNA & Coastal sand dunes along the Pacific Ocean \\
\hline
\end{tabular}

infraspecific taxa within S. simplex, except the narrowly endemic S. simplex subsp. simplex vars nana and chlorolepis. Leaf samples from individual clones spaced at least $2 \mathrm{~m}$ apart were preserved in silica gel. Population vouchers were deposited at the University of Michigan Herbarium (MICH) or the University of Waterloo Herbarium (WAT). In addition 


\section{J. A. Peirson et al.}

to field-sampled populations, leaf samples from two herbarium specimens of S. simplex var. simplex (samples $\mathrm{H} 2$ and H5 in Appendix S1) were included. Sample H5 represents the only accession from the south-western extreme of the distribution in Mexico.

\section{DNA extraction, PCR amplification and sequencing}

Total genomic DNA was isolated with the DNeasy Plant Mini Kit (Qiagen Corp., Valencia, CA, USA) following the manufacturer's protocols, except that herbarium samples were incubated overnight with $\beta$-mercaptoethanol. Several genomic samples required additional purification using glass milk technology (GeneClean, MP Biomedicals, Solon, OH, USA).

Our sequencing strategy for Solidago subsect. Humiles was twofold. First, single individuals from all 72 populations were sequenced to capture preliminary estimates of range-wide genetic diversity rather than to examine intrapopulation variation intensively (following Petit et al., 2005). Second, an additional eight individuals per population from 37 of those populations that represented the taxonomic and geographical breadth of the subsection were sequenced to assess intrapopulation genetic diversity.

Two chloroplast intergenic spacers $(\operatorname{trn} \mathrm{H}-p s b \mathrm{~A}$ and $\operatorname{trn} \mathrm{K}-$ rps16) were used for this study because of their polymorphism and consistent polymerase chain reaction (PCR) amplification [previous screening of the nuclear ribosomal internal transcribed spacer (ITS) region revealed almost no sequence variation across Solidago; J.A.P., unpubl. data]. The trn $\mathrm{H}-p s b \mathrm{~A}$ spacer was amplified and sequenced using the trnH-f and psbA-3f primers of Kress et al. (2005), and the $\operatorname{trnK}-r p s 16$ spacer was amplified and sequenced with primers trnK-F1 (5'-GCCGCACTTAAAAGCCGAG-3') and rps16-R1 (5'-CCCAATGAGCCGTCTATCG-3') designed specifically for this study. The PCR amplifications were carried out with Takara Ex $\mathrm{Taq}^{\mathrm{TM}}$ polymerase (Takara Bio Inc., Otsu, Shiga, Japan). The thermal cycle for $t r n \mathrm{H}-p s b \mathrm{~A}$ was $94{ }^{\circ} \mathrm{C}$ for $3 \mathrm{~min}$, followed by 40 cycles of $94{ }^{\circ} \mathrm{C}$ for $45 \mathrm{~s}, 55^{\circ} \mathrm{C}$ for $45 \mathrm{~s}$ and $72{ }^{\circ} \mathrm{C}$ for $3 \mathrm{~min}$, with a final extension at $72{ }^{\circ} \mathrm{C}$ for $10 \mathrm{~min}$. The thermal cycle for trnK-rps 16 was $94{ }^{\circ} \mathrm{C}$ for $3 \mathrm{~min}$, followed by 35 cycles of $94{ }^{\circ} \mathrm{C}$ for $45 \mathrm{~s}, 55^{\circ} \mathrm{C}$ for $1 \mathrm{~min}$ and $72{ }^{\circ} \mathrm{C}$ for $3 \mathrm{~min}$, with a final extension at $72{ }^{\circ} \mathrm{C}$ for $10 \mathrm{~min}$. Negative controls using water instead of genomic DNA were run with each PCR mix to check for contamination. PCR products were purified using ExoSAPIT (Affymetrix, Santa Clara, CA, USA) and sequenced using BigDye chemistry (Applied Biosystems Inc., Foster City, CA, USA) on an ABI 3730xl capillary sequencer.

\section{DNA sequence alignment, indel scoring and concatenation}

Sequence files were edited in Sequencher 4.6 (Genecodes Corp., Ann Arbor, MI, USA) and aligned automatically in Clustal X 2.0 (Larkin et al., 2007) using default parameters.
Final alignments were performed in $\mathrm{SE}_{\mathrm{E}} \mathrm{AL}$ 2.0a11 (available for download at http://tree.bio.ed.ac.uk/software/seal/) following recommendations for cpDNA spacer regions (Kelchner, 2000; Borsch et al., 2003). In the trnK-rps16 spacer, length variation in a poly-A region (from 9 to $14 \mathrm{bp}$ ) was removed because of the potential for non-homologous repeat patterns. In the $t r n \mathrm{H}-p s b \mathrm{~A}$ spacer, a variable region of mostly TA repeats (hotspot region sensu Borsch et al., 2003; Schlaepfer et al., 2008) was removed because of potential homoplasy. Also in the trn $\mathrm{H}-p s b \mathrm{~A}$ spacer, a $23 \mathrm{bp}$ inversion/ indel complex in three samples from population S60 was reverse-complemented and scored as a single mutational event.

The congruence of the $\operatorname{trn} \mathrm{K}-r p s 16$ and $t r n \mathrm{H}-p s b \mathrm{~A}$ spacers was tested with a partition homogeneity test (the incongruence length difference test of Farris et al., 1995) implemented in PAUP ${ }^{\star} 4.0 \mathrm{~b} 10$ (Sinauer Associates, Sunderland, MA, USA). Because the test was not significant (100 replicates; $P=0.45)$, the regions were concatenated into a single alignment file for all subsequent analyses. Based on recommendations in Simmons et al. (2007), indels in the concatenated data set were coded as single mutational events using a variation of modified complex indel coding (MCIC sensu Müller, 2006).

\section{Network construction and analyses}

Sequence data from all 368 individuals of Solidago subsect. Humiles were analysed in a statistical parsimony framework using the program TCs 1.21 (Clement et al., 2000). Haplotype identification and network reconstruction were performed using the MCIC coded data set with gaps treated as a fifth character and the default connections between haplotypes set at the $95 \%$ limit.

Genetic diversity parameters, including haplotype diversity $(h)$, indel diversity $\left(\pi_{\mathrm{I}}\right)$ and nucleotide diversity $\left(\pi_{\mathrm{S}}\right)$, were calculated for Solidago subsect. Humiles as a whole, for each species, and for infraspecific taxa within S. simplex using DNASP 4.0 (Rozas et al., 2003). To compare haplotype diversity between geographical regions, the number of haplotypes was standardized by rarefying to 40 individuals for each geographical region using the program CONTRIB 1.02 (Petit et al., 1998). Four broad geographical regions were recognized (see Table 1 and Appendix S1): western North America (WNA), southeastern Unites States and Southern Appalachians (SEUS), Great Lakes region (GL) and north-eastern North America (NE). To test for the presence of phylogeographical structure (sensu El Mousadik \& Petit, 1996; Pons \& Petit, 1996), $N_{\mathrm{ST}}$ (a measure of genetic differentiation that incorporates phylogenetic distance) was compared to permuted values of $G_{\mathrm{ST}}$ (an unordered measure of genetic differentiation that does not incorporate phylogenetic distance) with the program SPAGEDi 1.3 (Hardy \& Vekemans, 2002).

To test for a signature of population expansion across Solidago subsect. Humiles, a mismatch analysis (sensu Harpending et al., 1998) of the entire data set was conducted in 
ARLEQUin 3.5, with 1000 replicates of ARLEQUiN's parametric bootstrap method (Schneider \& Excoffier, 1999; Excoffier \& Lischer, 2010). As an additional test of population expansion, Tajima's D (Tajima, 1989) was calculated in ArLequin 3.5. The value of tau $(\tau)$ from the mismatch analysis was used to estimate the age of population expansion with the equation $t=\tau / 2 \mu$, where $t$ is the number of generations and $\mu$ is the substitution rate per generation for the combined spacer data (per-site rate $\times$ length of sequence). Two per-site mutation rates were used to give a range for the timing of expansion: a slower rate of $1.0 \times 10^{-9}$ substitutions/silent site/year (following Dick et al., 2007) and an order of magnitude faster rate of $1.0 \times 10^{-8}$ substitutions/silent site/year. A generation time of 2 years was used.

To assess the partitioning of genetic variation, an analysis of molecular variance (AMOVA; Excoffier et al., 1992) was performed using ARLEQuin 3.5, grouping populations by species, by species but with Solidago simplex divided into two subspecies, by geography without regard to taxonomy (see above), by ploidy without regard to taxonomy (diploid/polyploid), and by groupings from spatial analysis of molecular variance (SAMOVA; Dupanloup et al., 2002) for $K=5$ (see below). SAMOVA was used to analyse the geographical structuring of genetic variation in S. subsect. Humiles without assignments to a priori groups. For the SAMOVA, 37 populations of $S$. subsect. Humiles with intrapopulation sampling ( $n=333$ individuals) were analysed using $K=2$ to 15 simulated groups. Single accessions cannot be incorporated in SAMOVA and thus were not analysed.

\section{RESULTS}

\section{Chloroplast DNA diversity and population expansion}

The concatenated trnK-rps16 and $t r n \mathrm{H}-p s b \mathrm{~A}$ data set (including indels) had an aligned length of $1482 \mathrm{bp}$. The MCIC concatenated data set used in the statistical parsimony analysis had an aligned length of 1295 bp. Forty-six chloroplast haplotypes (GenBank accession numbers KC309690KC310057 for trnH-psbA and KC310058-KC310425 for trnK-rps16) were recovered from 368 individuals of Solidago subsect. Humiles (Table 2, Fig. 2, Appendix S2). Fifteen individuals possessed unique haplotypes (haplotypes 1, 10, 12, $22,25,26,32,34,39,40,42,43,44,45$ and 46). The overall topology of the statistical parsimony network and recovered groupings of haplotypes were consistent with separate maximum likelihood and Bayesian inference analyses of an expanded cpDNA haplotype data set with broader specieslevel sampling (Peirson, 2010).

Among the four geographical regions delimited in this study, the greatest number of haplotypes was recovered from western North America $(n=26)$. A total of 14 haplotypes were recovered from each the Great Lakes region and the south-eastern United States. The haplotype complement in north-eastern North America was considerably lower $(n=8)$. When rarefied to 40 individuals, regional haplotype
Table 2 Chloroplast genetic diversity within Solidago subsect. Humiles. Number of sampled populations $\left(N_{\mathrm{P}}\right)$, number of sampled individuals $\left(N_{\mathrm{I}}\right)$, number of haplotypes $\left(H_{\mathrm{P}}\right)$, haplotype diversity $(h)$, number of segregating indels $(I)$, indel diversity $\left(\pi_{\mathrm{I}}\right)$, number of segregating sites $(S)$ and nucleotide diversity $\left(\pi_{\mathrm{S}}\right)$ are indicated for the subsection as a whole, for each species, for infraspecific taxa within $S$. simplex, and for populations of S. simplex subsp. simplex from western (W) and eastern (E) North America.

\begin{tabular}{lrrrlrlrl}
\hline Taxon & $N_{\mathrm{P}}$ & $N_{\mathrm{I}}$ & $H_{\mathrm{P}}$ & $h$ & $I$ & $\pi_{\mathrm{I}}$ & \multicolumn{1}{l}{$S$} & $\pi_{\mathrm{S}}$ \\
\hline Solidago subsect. & 72 & 368 & 46 & 0.93 & 42 & 0.0023 & 28 & 0.0015 \\
$\quad$ Humiles & & & & & & & & \\
Solidago arenicola & 6 & 30 & 7 & 0.81 & 7 & 0.0019 & 4 & 0.0009 \\
Solidago kralii & 2 & 10 & 3 & 0.51 & 2 & 0.0007 & 1 & 0.0002 \\
Solidago plumosa & 1 & 9 & 2 & 0.22 & 3 & 0.0005 & 2 & 0.0003 \\
Solidago simplex & 57 & 289 & 35 & 0.90 & 35 & 0.0021 & 23 & 0.0014 \\
$\quad$ subsp. simplex & 26 & 138 & 22 & 0.89 & 28 & 0.0024 & 14 & 0.0015 \\
$\quad$ var. simplex (W) & 21 & 109 & 19 & 0.86 & 28 & 0.0026 & 12 & 0.0015 \\
$\quad$ var. simplex (E) & 5 & 29 & 6 & 0.74 & 8 & 0.0012 & 7 & 0.0012 \\
$\quad$ subsp. randii & 31 & 151 & 20 & 0.85 & 20 & 0.0013 & 15 & 0.0014 \\
$\quad$ var. gillmanii & 6 & 38 & 5 & 0.70 & 7 & 0.0015 & 4 & 0.0011 \\
$\quad$ var. ontarioensis & 8 & 48 & 9 & 0.84 & 10 & 0.0016 & 8 & 0.0014 \\
$\quad$ var. monticola & 6 & 22 & 6 & 0.74 & 5 & 0.0011 & 6 & 0.0007 \\
$\quad$ var. racemosa & 11 & 43 & 12 & 0.79 & 10 & 0.0007 & 8 & 0.0013 \\
Solidago spathulata & 6 & 30 & 7 & 0.76 & 6 & 0.0015 & 3 & 0.0004 \\
\hline
\end{tabular}

diversity was as follows: western North America, 13.9; southeastern United States, 11.5; Great Lakes region, 10.2; and north-eastern North America, 6.5.

Mismatch analysis and the test of selective neutrality of the complete data set supported the hypothesis that Solidago subsect. Humiles underwent an historical population expansion (sum of squared deviation $=0.01, P=0.24$; Harpending's raggedness index $=0.02, P=0.17$; Tajima's $D=-1.4$, $P=0.05)$. The population expansion model produced an estimate of tau $(\tau)=5.6$ and thus an estimated age of population expansion for S. subsect. Humiles of 0.48-4.4 Ma.

\section{Phylogeographical structure $\left(N_{\mathrm{ST}}\right.$ versus $\left.G_{\mathrm{ST}}\right)$ and AMOVA}

$N_{\mathrm{ST}}$ of Solidago subsect. Humiles (0.66) was significantly higher than $G_{\mathrm{ST}}(0.62)$ at a global level $(P=0.02)$, and for all grouping schemes tested (Table 3 ), indicating significant phylogeographical structure in the data set regardless of the grouping scheme used.

AMOVA indicated generally weak partitioning of haplotype diversity with regard to taxonomic boundaries, geography and ploidy level, with the sum of intragroup and intrapopulation diversity explaining between $78.5 \%$ and $91.8 \%$ of the variation (Table 3 ). These results were consistent with visual inspection of the haplotype distribution data that showed haplotype sharing among species, geographical regions and ploidy levels (Fig. 3). The population structure identified by the SAMOVA ( $K=5$, see below) produced substantially more between group genetic differentiation than any of the a priori groupings (Table 3), further highlighting 


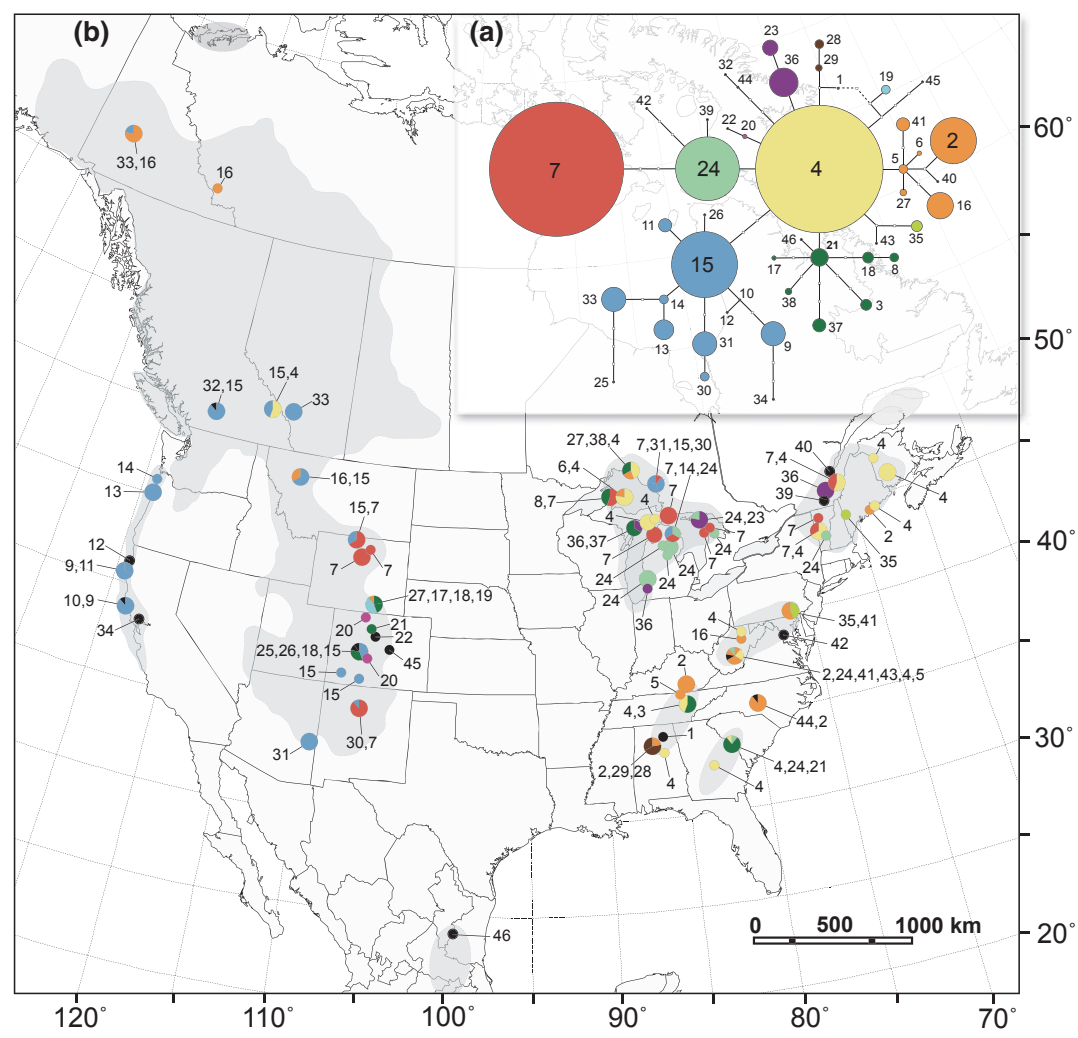

Figure 2 (a) Statistical parsimony network of 46 cpDNA haplotypes recovered from 368 accessions of Solidago subsect. Humiles. Haplotype circle area represents relative frequency. Dashed lines indicate alternative connections; hypothesized haplotypes are indicated by white squares. Haplotypes were arbitrarily assigned numbers 1-46 and colour-coded to indicate major groups. Haplotypes unique to a single individual are coloured black. (b) Geographical distribution of haplotypes in North America. The haplotype complement at each sampling locality is indicated; haplotypes are ordered from least to most common. Generalized taxon distributions are indicated by grey shading as in Fig. 1.

Table 3 Results of the analyses of molecular variance (AMOVA) and the test of phylogeographical structure $\left(N_{\mathrm{ST}}>G_{\mathrm{ST}}\right)$ of cpDNA sequence data from Solidago subsect. Humiles populations. Groupings were as follows: (a) by species; (b) by species but with $S$. simplex divided into two subspecies; (c) by geography with four regions of North America recognized (see text and Table 1 and Appendix S1 for regions); (d) by ploidy (diploid versus polyploid); and (e) by groupings from SAMOVA (for $K=5$ ).

\begin{tabular}{|c|c|c|c|c|c|c|c|}
\hline Grouping & d.f. & Fixation indices & $\%$ of variation & $P$ & $N_{\mathrm{ST}}$ & $G_{\mathrm{ST}}$ & $P$ \\
\hline \multirow[t]{3}{*}{ (a) } & 4 & $F_{\mathrm{CT}}=0.22$ & 21.5 & 0.003 & 0.50 & 0.33 & $<0.001$ \\
\hline & 32 & $F_{\mathrm{SC}}=0.63$ & 49.2 & $<0.001$ & - & - & - \\
\hline & 296 & $F_{\mathrm{ST}}=0.71$ & 29.3 & $<0.001$ & - & - & - \\
\hline \multirow[t]{3}{*}{ (b) } & 5 & $F_{\mathrm{CT}}=0.16$ & 16.2 & 0.001 & 0.44 & 0.30 & 0.002 \\
\hline & 31 & $F_{\mathrm{SC}}=0.62$ & 51.7 & $<0.001$ & - & - & - \\
\hline & 296 & $F_{\mathrm{ST}}=0.68$ & 32.1 & $<0.001$ & - & - & - \\
\hline \multirow[t]{3}{*}{ (c) } & 3 & $F_{\mathrm{CT}}=0.14$ & 13.6 & $<0.001$ & 0.18 & 0.12 & 0.012 \\
\hline & 33 & $F_{\mathrm{SC}}=0.62$ & 53.9 & $<0.001$ & - & - & - \\
\hline & 296 & $F_{\mathrm{ST}}=0.67$ & 32.5 & $<0.001$ & - & - & - \\
\hline \multirow[t]{3}{*}{ (d) } & 1 & $F_{\mathrm{CT}}=0.08$ & 8.2 & $<0.001$ & 0.11 & 0.04 & 0.002 \\
\hline & 35 & $F_{\mathrm{SC}}=0.65$ & 59.4 & $<0.001$ & - & - & - \\
\hline & 296 & $F_{\mathrm{ST}}=0.68$ & 32.4 & 0.005 & - & - & - \\
\hline \multirow[t]{3}{*}{ (e) } & 4 & $F_{\mathrm{CT}}=0.48$ & 48.1 & $<0.001$ & 0.73 & 0.53 & $<0.001$ \\
\hline & 32 & $F_{\mathrm{SC}}=0.51$ & 26.3 & $<0.001$ & - & - & - \\
\hline & 296 & $F_{\mathrm{ST}}=0.74$ & 25.6 & $<0.001$ & - & - & - \\
\hline
\end{tabular}

$F_{\mathrm{CT}}=$ differentiation among groups of populations, $F_{\mathrm{SC}}=$ differentiation among populations within groups, $F_{\mathrm{ST}}=$ differentiation among individuals within populations. 


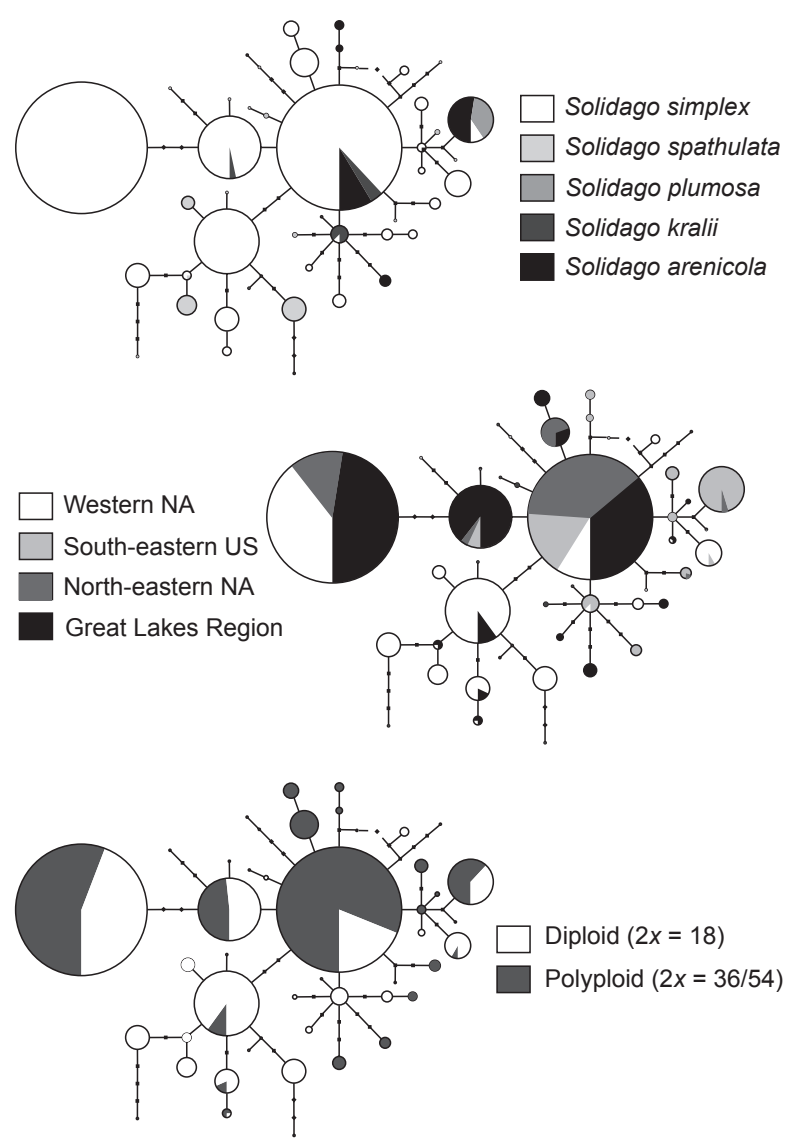

Figure 3 Statistical parsimony cpDNA haplotype networks of Solidago subsect. Humiles, showing distribution of haplotypes among species (top), geographical regions of North America (NA) (middle), and ploidy levels (bottom). See text for description of geographical regions. Ploidy data are from Peirson et al. (2012).

the relatively shallow levels of taxonomic, geographical and ploidy-related structuring of genetic diversity (Fig. S1 in Appendix S3; see population assignments to SAMOVA groups $1-5$ in Appendix S1).

\section{Spatial analysis of molecular variance}

The optimal number of groups indicated by SAMOVA was $K=5\left(F_{\mathrm{CT}}=0.48 ; 0\right.$ singleton populations $)$. Higher levels of $K$ produced modestly higher fixation indices but also included single-population groups and were thus suboptimal (Table S1 in Appendix S3). The genetic structure (Fig. S1 in Appendix S3) identified by the SAMOVA $(K=5)$ included one large grouping of 26 populations that comprised multiple species and ploidy levels and populations in all four geographical regions (Group 1). Three of the smaller groupings ranged in size from 2-3 populations per group and were composed of regionally proximal sets of populations. Groups 2 and 4 included Solidago simplex var. simplex and S. spathulata from western North America, while Group 3 included S. plumosa and one population of S. arenicola in the south-eastern United States. Group 5 comprised two populations of diploid S. simplex var. simplex from the northern Rocky Mountains and New Mexico and two populations of tetraploid S. simplex var. gillmanii from the Great Lakes region.

\section{DISCUSSION}

\section{Structuring of genetic diversity}

Tests of phylogeographical structure indicated that there was significant structuring of cpDNA diversity within Solidago subsect. Humiles, but AMOVA revealed that groupings of populations by taxonomy, geography and ploidy explained relatively little of the partitioning of genetic diversity within the subsection. Of the grouping schemes tested with AMOVA, the partitioning based on ploidy explained the smallest amount of variation $\left(F_{\mathrm{CT}}=8.2 \%\right)$. SAMOVA (at $K=5$ ) produced substantially higher between-group measures of differentiation than any of the a priori groupings but revealed shallow geographical structuring of cpDNA variation. Twenty-six of the 37 populations in the SAMOVA were incorporated into a widely distributed group that included populations of multiple species and ploidy levels from across North America (Fig. S1).

Consistent with the weak partitioning of cpDNA diversity, our range-wide cpDNA data revealed that six haplotypes were shared among species in Solidago subsect. Humiles (Fig. 3). Broader species-level sampling in Solidago has also uncovered haplotype sharing among more distantly related species from different subsections (Schlaepfer et al., 2008; Peirson, 2010; Laureto \& Barkman, 2011). The second most common haplotype in our study, haplotype 4 , was present in S. simplex (both $2 x$ and $4 x$ individuals), S. arenicola and S. kralii; and it was widely distributed throughout eastern North America and into south-western Canada. This haplotype has also been found in S. hispida and S. rigida, species in different subsections of the genus (Peirson, 2010). Haplotype 4 occupies a central position in the network (Fig. 2), suggesting that it is likely to be an ancestral haplotype.

The patterns of cpDNA diversity emerging from Solidago, including the sharing of likely ancestral haplotypes across species, are similar to patterns found in recently diversified groups like North American rock cresses (Boechera, Brassicaceae; Kiefer et al., 2009; Kiefer \& Koch, 2012) and New World barleys (Hordeum, Poaceae; Jakob \& Blattner, 2006). Past hybridization and chloroplast capture have also been important factors in the structuring of cpDNA in some species, such as red and silver maple (Acer rubrum and A. saccharinum), which initially diverged in the Pliocene but share cpDNA haplotypes in areas of syntopy (Saeki et al., 2011). It is likely that both the retention of ancestral polymorphism and gene flow have been factors in haplotype sharing among species in $S$. subsect. Humiles.

Weak partitioning of cpDNA diversity, sharing of haplotypes between species, and a potentially recent population 


\section{J. A. Peirson et al.}

expansion (0.48-4.4 Ma) all support treating Solidago subsect. Humiles as a species complex and including these closely related taxa in a single phylogeographical analysis (similar to the approach used by Scotti-Saintagne et al., 2013).

\section{Holocene biogeography}

European and North American phylogeographical studies have highlighted the importance of southern refugia for many temperate trees and forest understorey plants (reviewed in Taberlet et al., 1998; Soltis et al., 2006), but patterns emerging from phylogeographical studies of widespread and northern-temperate and boreal plants suggest that the late Pleistocene and Holocene histories of some species included survival in northern/periglacial refugia (e.g. McLachlan et al., 2005; Ronikier et al., 2008; Beatty \& Provan, 2010, 2011; Michl et al., 2010; Allen et al., 2012). Our results indicate that Solidago simplex survived glaciation in multiple refugia in different regions of the continent and that formerly glaciated areas of eastern North America are actually a mixing ground for migrants from western North America, northern refugia around the perimeter of the ice sheets, and possibly from the south-eastern United States.

The genetic structure identified by the SAMOVA grouped all but four populations of Solidago subsect. Humiles in eastern North America into the widespread group of 26 populations. Yet despite the grouping from SAMOVA and the fact that glaciated eastern North America and the south-eastern United States harboured similar numbers of haplotypes, the haplotype complements between the regions were quite different. Of the 14 haplotypes found in the Great Lakes region, only haplotypes 4 and 24 were present in the south-eastern United States. Haplotype 4 is an ancestral haplotype that occupies the centre of the network and is common and widely distributed taxonomically and geographically. Thus the distribution of this haplotype provides little explanatory power, but it is possible that individuals with this haplotype recolonized glaciated areas from the south. Haplotype 24 is common in Great Lakes region S. simplex populations but is rare in the south-eastern United States, recovered from single individuals of S. kralii (South Carolina) and S. simplex var. racemosa (West Virginia). Of the eight haplotypes found in north-eastern North America, four were shared with the south-eastern United States. Of these, only haplotype 4 was common in north-eastern North America.

Our data indicate that the south-eastern United States was not the primary source of post-glacial migrants for formerly glaciated areas of eastern North America. The Great Lakes region had a higher genetic similarity to western North America ( $n=7$ shared haplotypes) and north-eastern North America ( $n=4$ shared haplotypes) than to the south-eastern United States. The presence of four 'western' haplotypes (14, 15, 30, 31 in Figs 2-3) in the northern Great Lakes region supports biogeographical hypotheses of a migration corridor connecting the western Cordillera and the Great Lakes region
(Fernald, 1925; Marie-Victorin, 1938; Marquis \& Voss, 1981), and the SAMOVA confirmed a linkage between the glaciated Great Lakes region and the Rocky Mountain region, south of the Cordilleran ice sheet. Our data do not support Ringius \& Semple's (1987) hypothesis that diploid S. simplex recolonized glaciated eastern North America from a refugium in Beringia (consistent with patterns found in some other widespread boreal species, e.g. Breen et al., 2012; Wróblewska, 2012). None of the haplotypes recovered from northwestern Canada were present in the Great Lakes region. Our sampling in western Canada, however, was not extensive enough to fully explain patterns of Holocene recolonization there.

Our analyses identified haplotypes that were restricted to formerly glaciated regions of eastern North America (haplotypes $6,8,23,37,38$ in the Great Lakes region; 39, 40 in north-eastern North America; and 36 shared by both regions). These data from Solidago simplex support the possibility that glaciated eastern North America was recolonized in part by migrants that survived glaciation in northern refugia closer to the ice margin, where the species no longer occurs. This pattern in S. simplex is congruent with findings from other widespread and northern-temperate and boreal plant and animal taxa in North America (e.g. Dobes et al., 2004; McLachlan et al., 2005; Beatty \& Provan, 2010, 2011; van Els et al., 2012). Dobes et al. (2004) hypothesized a cryptic refugium near the Great Lakes region for a widespread montane and boreal rockcress complex (Arabis drummondii-A. holboellii complex, Brassicaceae), and Beatty \& Provan (2011) suggested that saprotrophic pinesap (Monotropa hypopithys, Monotropaceae) survived glaciation in multiple refugia, possibly including the unglaciated 'Driftless Area' of the upper Midwestern United States. Together these studies suggest that northern refugia were important contributors to post-glacial colonization in North America, especially for temperate and boreal herbs.

\section{Evolution of polyploidy}

Our phylogeographical data rejected a single origin of polyploidy in Solidago simplex and indicated more generally that polyploids in S. subsect. Humiles probably formed numerous times. Polyploids in Solidago subsect. Humiles harboured 24 chloroplast haplotypes that do not form a single clade; 8 of those haplotypes are shared with diploids while 16 are present in polyploids only (Fig. 3). From a theoretical standpoint, a single origin of polyploidy would result in a single ancestral chloroplast haplotype, and descendants of the original polyploid should form a single lineage. Therefore, the lack of monophyly of polyploids in our study strongly suggests that they evolved multiple times. While it is also possible that gene flow and chloroplast capture from other tetraploid Solidago species created the patterns uncovered in S. subsect. Humiles, our data do not strongly support that scenario. Of the 16 polyploid-only haplotypes recovered in our study, only two have been found in goldenrod species 
outside of S. subsect. Humiles (Peirson, 2010). Peirson et al. (2012) also argued that the recurrent origin of polyploids in S. simplex was likely, in part because of the rare occurrence of cryptic tetraploids in otherwise diploid populations. They suggested that while those data did not indicate high levels of recurrent polyploidy, they did show that polyploid formation in S. simplex could occur on contemporary ecological timescales.

The likely recurrent evolution of polyploids in Solidago subsect. Humiles is consistent with results from studies of other goldenrod species. Schlaepfer et al. (2008) concluded that multiple polyploidization events were significantly more likely than a single origin of tetraploids in S. gigantea, and they inferred as many as seven independent origins in eastern North America. Similarly, Halverson et al. (2008) rejected the hypothesis that polyploid cytotypes in S. altissima had a single, ancient origin. While genus-wide phylogenetic data are largely lacking for Solidago (see discussion in Beck et al., 2004), recurrent formation of polyploids seems probable in a number of species (Peirson et al., 2012). These results from Solidago are consistent with numerous molecular phylogenetic studies that have demonstrated that the recurrent formation of polyploid lineages is the norm in many plants (e.g. Rebernig et al., 2010; Symonds et al., 2010; Artyukova et al., 2011).

While our demographic analyses placed the main population expansion in S. subsect. Humiles between the late Pleistocene and early Pliocene (well before the Wisconsinan glacial period hypothesis of Ringius \& Semple, 1987), our phylogeographical data also support the evolution of polyploid taxa within a Holocene timeframe. Phylogeographical results revealed that diploid S. simplex in the Great Lakes region shared haplotypes with the two tetraploid varieties that are endemic to post-glacial habitats there. In addition, the mixedploidy populations found by Peirson et al. (2012) were all in the formerly glaciated Great Lakes region. The presence of newly formed, cryptic tetraploids and the sharing of haplotypes between diploids and endemic polyploids suggest that this formerly glaciated region is an active zone of recurrent polyploid formation. It also suggests that the two edaphic endemic polyploids in the Great Lakes region evolved in situ during the Holocene. These data for Solidago support the hypothesis of polyploidization as a source of adaptive genetic variation and speciation in novel and post-glacial habitats (Stebbins, 1974; Ramsey, 2011; Parisod, 2012).

\section{CONCLUSIONS}

Our results indicate that members of Solidago subsect. Humiles survived glaciation in multiple refugia. Formerly glaciated areas of eastern North America, like the Great Lakes region, are a mixing ground for Solidago and were most likely recolonized by migrants from western North America and from refugia near the perimeter of the ice margin. Refugia in the south-eastern United States had only limited involvement in recolonization of these more northerly regions. The glacial biogeography of $S$. simplex is congruent with patterns emerging from other North American temperate and boreal herbs and does not adhere to palaeoecological models of glacial survival in isolated southern refugia or to phylogeographical patterns found in many temperate trees and forest understorey species. These results highlight the dynamic and individualistic nature of post-glacial recolonization, and they also emphasize the importance of taxon selection when attempting to elucidate the broader picture of Holocene biogeography in North America.

The results of this study of $S$. subsect. Humiles also raise the question of whether Quaternary climatic cycles and associated vegetation dynamics promoted or hindered differentiation and speciation in this complex of goldenrods. The likely recurrent formation of polyploid lineages supports the hypothesis of adaptive, polyploid diversification in the group, and the probable Holocene evolution of edaphic endemic polyploids in post-glacial habitats in the Great Lakes region suggests rapid differentiation since the Last Glacial Maximum. To address this question more thoroughly, however, will require a well-resolved Solidago phylogeny and additional genetic data in the S. simplex species complex. Recent advances in next-generation sequencing hold significant promise for recently evolved and cytologically complex groups such as Solidago (Hudson, 2008; Emerson et al., 2010). An approach similar to the one used by Griffin et al. (2011) to examine the evolution of polyploid Australian alpine grasses will be essential to untangling the complicated evolution of Solidago simplex and other species complexes in Solidago.

\section{ACKNOWLEDGEMENTS}

We thank B. Bennett and J. Semple for providing leaf material, A. Larson for assistance in the field, and the National Park Service and numerous state agencies for granting permission to collect specimens on public lands. We acknowledge the curators and staff of the following herbaria: ALA, ARIZ, ASU, BRIT, BRY, COLO, GH, MAINE, MO, MONTU, MSC, MT, NMC, NYS, QFA, RM, TEX, UBC, UMBS, UTC, VT, WIS and WVA. Financial assistance was provided to J. Peirson by The University of Michigan, The Michigan Botanical Foundation, The Hanes Fund for Botanical Research, The American Society of Plant Taxonomists, The American Philosophical Society and The National Science Foundation (Doctoral Dissertation Improvement Grant DEB-0808242).

\section{REFERENCES}

Allen, G.A., Marr, K.L., McCormick, L.J. \& Hedba, R.J. (2012) The impact of Pleistocene climate change on an ancient arctic-alpine plant: multiple lineages of disparate history in Oxyria digyna. Ecology and Evolution, 2, 649665. 
Artyukova, E.V., Kozyrenko, M.M., Kholina, A.B. \& Zhuravlev, Y.N. (2011) High chloroplast haplotype diversity in the endemic legume Oxytropis chankaensis may result from independent polyploidization events. Genetica, 139, 221232.

Beatty, G.E. \& Provan, J. (2010) Refugial persistence and postglacial recolonization of North America by the coldtolerant herbaceous plant Orthilia secunda. Molecular Ecology, 19, 5009-5021.

Beatty, G.E. \& Provan, J. (2011) Phylogeographic analysis of North American populations of the parasitic herbaceous plant Monotropa hypopitys L. reveals a complex history of range expansion from multiple late glacial refugia. Journal of Biogeography, 38, 1585-1599.

Beck, J.B., Nesom, G.L., Calie, P.J., Baird, G.I., Small, R.L. \& Schilling, E.E. (2004) Is subtribe Solidagininae (Asteraceae) monophyletic? Taxon, 53, 691-698.

Bennett, K.D., Tzedakis, P.C. \& Willis, K.J. (1991) Quaternary refugia of north European trees. Journal of Biogeography, 18, 103-115.

Borsch, T., Hilu, K.W., Quandt, D., Wilde, V., Neinhuis, C. \& Barthlott, W. (2003) Noncoding plastid trnT-trnF sequences reveal a well resolved phylogeny of basal angiosperms. Journal of Evolutionary Biology, 16, 558-576.

Braun, E.L. (1928) Glacial and post-glacial plant migrations indicated by relic colonies of southern Ohio. Ecology, 9, 284-302.

Breen, A.L., Murray, D.F. \& Olson, M.S. (2012) Genetic consequences of glacial survival: the late Quaternary history of balsam poplar (Populus balsamifera L.) in North America. Journal of Biogeography, 39, 918-928.

Clement, M., Posada, D. \& Crandall, K.A. (2000) TCS: a computer program to estimate gene genealogies. Molecular Ecology, 9, 1657-1659.

Davis, M.B. (1983) Holocene vegetational history of the eastern United States. Late-Quaternary environments of the United States (ed. by H.E.J. Wright), pp. 166-181. University of Minnesota Press, Minneapolis, MN.

Dick, C.W., Bermingham, E., Lemes, M.R. \& Gribel, R. (2007) Extreme long-distance dispersal of the lowland tropical rainforest tree Ceiba pentandra L. (Malvaceae) in Africa and the Neotropics. Molecular Ecology, 16, 30393049.

Dobes, C.H., Mitchell-Olds, T. \& Koch, M.A. (2004) Extensive chloroplast haplotype variation indicates Pleistocene hybridization and radiation of North American Arabis drummondii, A. $\times$ divaricarpa, and A. holboellii (Brassicaceae). Molecular Ecology, 13, 349-370.

Dupanloup, I., Schneider, S. \& Excoffier, L. (2002) A simulated annealing approach to define the genetic structure of populations. Molecular Ecology, 11, 2571-2581.

El Mousadik, A. \& Petit, R.J. (1996) Chloroplast DNA phylogeography of the argan tree of Morocco. Molecular Ecology, 5, 547-555.

van Els, P., Cicero, C. \& Klicka, J. (2012) High latitudes and high genetic diversity: phylogeography of a widespread boreal bird, the gray jay (Perisoreus canadensis). Molecular Phylogenetics and Evolution, 63, 456-465.

Emerson, K.J., Merz, C.R., Catchen, J.M., Hohenlohe, P.A., Cresko, W.A., Bradshaw, W.E. \& Holzapfel, C.M. (2010) Resolving postglacial phylogeography using high-throughput sequencing. Proceedings of the National Academy of Sciences USA, 107, 16196-16200.

Excoffier, L. \& Lischer, H.E.L. (2010) Arlequin suite ver. 3.5: a new series of programs to perform population genetics analyses under Linux and Windows. Molecular Ecology Resources, 10, 564-567.

Excoffier, L., Smouse, P.E. \& Quattro, J.M. (1992) Analysis of molecular variance inferred from metric distances among DNA haplotypes: application to human mitochondrial-DNA restriction data. Genetics, 131, 479-491.

Farris, J.S., Källersjö, M., Kluge, A.G. \& Bult, C. (1995) Constructing a significance test for incongruence. Systematic Biology, 44, 570-572.

Fernald, M.L. (1925) Persistence of plants in unglaciated areas of boreal America. Memoirs of the American Academy of Arts and Sciences, 15, 241-342.

Griffin, P.C., Robin, C. \& Hoffmann, A.A. (2011) A nextgeneration sequencing method for overcoming the multiple gene copy problem in polyploid phylogenetics, applied to Poa grasses. BMC Biology, 9, 19.

Halverson, K., Heard, S.B., Nason, J.D. \& Stireman, J.O. (2008) Origins, distribution, and local co-occurrence of polyploid cytotypes in Solidago altissima (Asteraceae). American Journal of Botany, 95, 50-58.

Hardy, O.J. \& Vekemans, X. (2002) SPAGeDi: a versatile computer program to analyse spatial genetic structure at the individual or population levels. Molecular Ecology Notes, 2, 618-620.

Harpending, H.C., Batzer, M.A., Gurven, M., Jorde, L.B., Rogers, A.R. \& Sherry, S.T. (1998) Genetic traces of ancient demography. Proceedings of the National Academy of Sciences USA, 95, 1961-1967.

Hewitt, G.M. (1996) Some genetic consequences of ice ages, and their role in divergence and speciation. Biological Journal of the Linnean Society, 58, 247-276.

Hewitt, G.M. (1999) Post-glacial re-colonization of European biota. Biological Journal of the Linnean Society, 68, 87-112.

Hewitt, G.M. (2000) The genetic legacy of the Quaternary ice ages. Nature, 405, 907-913.

Hewitt, G.M. (2003) Ice ages: their impact on species distributions and evolution. Evolution of planet Earth (ed. by L.J. Rothschild and A.M. Lister), pp. 339-361. Academic Press, London.

Hudson, M.E. (2008) Sequencing breakthroughs for genomic ecology and evolutionary biology. Molecular Ecology Resources, 8, 3-17.

Huntley, B. \& Webb, T., III (1989) Migration: species' response to climate variations caused by changes in the earth's orbit. Journal of Biogeography, 16, 5-19.

Jakob, S.S. \& Blattner, F.R. (2006) A chloroplast genealogy of Hordeum (Poaceae): long-term persisting haplotypes, 
incomplete lineage sorting, regional extinction, and the consequences for phylogenetic inference. Molecular Biology and Evolution, 23, 1602-1612.

Jaramillo-Correa, J.P., Beaulieu, J., Khasa, D.P. \& Bousquet, J. (2009) Inferring the past from the present phylogeographic structure of North American forest trees: seeing the forest for the genes. Canadian Journal of Forest Research, 39, 286-307.

Kelchner, S.A. (2000) The evolution of non-coding chloroplast DNA and its application in plant systematics. Annals of the Missouri Botanical Garden, 87, 482-498.

Kiefer, C. \& Koch, M.A. (2012) A continental-wide perspective: the genepool of nuclear encoded ribosomal DNA and single-copy gene sequences in North American Boechera (Brassicaceae). PLoS ONE, 7, e36491.

Kiefer, C., Dobes, C., Sharbel, T.F. \& Koch, M.A. (2009) Phylogeographic structure of the chloroplast DNA gene pool in North American Boechera - a genus and continental-wide perspective. Molecular Phylogenetics and Evolution, 52, 303-311.

Kress, W.J., Wurdack, K.J., Zimmer, E.A., Weigt, L.A. \& Janzen, D.H. (2005) Use of DNA barcodes to identify flowering plants. Proceedings of the National Academy of Sciences USA, 102, 8369-8374.

Larkin, M.A., Blackshields, G., Brown, N.P., Chenna, R., McGettigan, P.A., McWilliam, H., Valentin, F., Wallace, I.M., Wilm, A., Lopez, R., Thompson, J.D., Gibson, T.J. \& Higgins, D.G. (2007) Clustal W and Clustal X version 2.0. Bioinformatics, 23, 2947-2948.

Latham, R.E. \& Ricklefs, R.E. (1993) Continental comparisons of temperate-zone tree species diversity. Species diversity in ecological communities (ed. by R.E. Ricklefs and D. Schluter), pp. 294-314. University of Chicago Press, Chicago.

Laureto, P.J. \& Barkman, T.J. (2011) Nuclear and chloroplast DNA suggest a complex single origin for the threatened allopolyploid Solidago houghtonii (Asteraceae) involving reticulate evolution and introgression. Systematic Botany, 36, 209-226.

Marie-Victorin, F. (1938) Phytogeographical problems of eastern Canada. The American Midland Naturalist, 19, 489-558.

Marquis, R.J. \& Voss, E.G. (1981) Distributions of some western North American plants disjunct in the Great Lakes region. Michigan Botanist, 20, 53-82.

McLachlan, J.S., Clark, J.S. \& Manos, P.S. (2005) Molecular indicators of tree migration capacity under rapid climate change. Ecology, 86, 2088-2098.

Michl, T., Huck, S., Schmitt, T., Liebrich, A., Haase, P. \& Büdel, B. (2010) The molecular population structure of the tall forb Cicerbita alpina (Asteraceae) supports the idea of cryptic glacial refugia in central Europe. Botanical Journal of the Linnean Society, 164, 142-154.

Müller, K. (2006) Incorporating information from lengthmutational events into phylogenetic analysis. Molecular Phylogenetics and Evolution, 38, 667-676.
Parisod, C. (2012) Polyploids integrate genomic changes and ecological shifts. New Phytologist, 193, 297-300.

Peirson, J.A. (2010) Biogeography, ecology, and evolution of the endemic vascular flora of the glaciated Great Lakes region: a case study of the Solidago simplex species complex. PhD Thesis, The University of Michigan, Ann Arbor, MI.

Peirson, J.A., Reznicek, A.A. \& Semple, J.C. (2012) Polyploidy, infraspecific cytotype variation, and speciation in goldenrods: the cytogeography of Solidago subsect. Humiles (Asteraceae) in North America. Taxon, 61, 197-210.

Petit, R.J., El Mousadik, A. \& Pons, O. (1998) Identifying populations for conservation on the basis of genetic markers. Conservation Biology, 12, 844-855.

Petit, R.J., Aguinagalde, I., Beaulieu, J.L., Bittkau, C., Brewer, S., Cheddadi, R., Ennos, R., Fineschi, S., Grivet, D., Lascoux, M., Mohanty, A., Muller-Starck, G., Demesure, B., Palme, A., Martin, J.P., Rendell, S. \& Vendramin, G.G. (2003) Glacial refugia: hotspots but not melting pots of genetic diversity. Science, 300, 1563-1565.

Petit, R.J., Duminil, J., Fineschi, S., Hampe, A., Salvini, D. \& Vendramin, G.G. (2005) Comparative organization of chloroplast, mitochondrial, and nuclear diversity in plant populations. Molecular Ecology, 14, 689-701.

Pons, O. \& Petit, R.J. (1996) Measuring and testing genetic differentiation with ordered versus unordered alleles. Genetics, 144, 1237-1245.

Prentice, I.C. (1986) Vegetation responses to past climate variation. Vegetatio, 67, 131-141.

Ramsey, J. (2011) Polyploidy and ecological adaptation in wild yarrow. Proceedings of the National Academy of Sciences USA, 108, 7096-7101.

Rebernig, C.A., Weiss-Schneeweiss, H., Schneeweiss, G.M., Schönswetter, P., Obermayer, R., Villaseñor, J.L. \& Stuessy, T.F. (2010) Quaternary range dynamics and polyploid evolution in an arid brushland plant species (Melampodium cinereum, Asteraceae). Molecular Phylogenetics and Evolution, 54, 594-606.

Ringius, G.S. \& Semple, J.C. (1987) Cytogeography of the Solidago spathulata-glutinosa complex (Compositae, Astereae). Canadian Journal of Botany, 65, 2458-2462.

Ronikier, M., Costa, A., Aguilar, J.F., Feliner, G.N., Küpfer, P. \& Mirek, Z. (2008) Phylogeography of Pulsatilla vernalis (L.) Mill. (Ranunculaceae): chloroplast DNA reveals two evolutionary lineages across central Europe and Scandinavia. Journal of Biogeography, 35, 1650-1664.

Rowe, K.C., Heske, E.J., Brown, P.W. \& Paige, K.N. (2004) Surviving the ice: northern refugia and postglacial colonization. Proceedings of the National Academy of Sciences USA, 101, 10355-10359.

Rozas, J., Sánchez-DelBarrio, J.C., Messequer, Z. \& Rozas, R. (2003) DnaSP, DNA polymorphism analyses by the coalescent and other methods. Bioinformatics, 19, 2496-2497.

Saeki, I., Dick, C.W., Barnes, B.V. \& Murakami, N. (2011) Comparative phylogeography of red maple (Acer rubrum L.) and silver maple (Acer saccharinum L.): impacts of 
habitat specialization, hybridization, and glacial history. Journal of Biogeography, 38, 1-14.

Schlaepfer, D.R., Edwards, P.J., Widmer, A. \& Billeter, R. (2008) Phylogeography of native ploidy levels and invasive tetraploids of Solidago gigantea. Molecular Ecology, 17, 5245-5256.

Schneider, S. \& Excoffier, L. (1999) Estimation of past demographic parameters from the distribution of pairwise differences when the mutation rates vary among sites: application to human mitochondrial DNA. Genetics, 152, 1079-1089.

Scotti-Saintagne, C., Dick, C.W., Caron, H., Guichoux, E., Vendramin, G.G., Buonanici, A., Duret, A., Sire, P., Valencia, R., Lemes, M.R., Gribel, R. \& Scotti, I. (2013) Phylogeography of a species complex of lowland Neotropical rain forest trees (Carapa, Meliaceae). Journal of Biogeography, 40, 676-692.

Semple, J.C. \& Cook, R.E. (2006) Solidago. Flora of North America: Asteraceae (ed. by F.O.N.A.E. Committee), pp. 107-166. Oxford University Press, New York.

Shafer, A.B., Cullingham, C.I., Côté, S.D. \& Coltman, D.W. (2010) Of glaciers and refugia: a decade of study sheds new light on the phylogeography of northwestern North America. Molecular Ecology, 19, 4589-4621.

Simmons, M.P., Müller, K. \& Norton, A.P. (2007) The relative performance of indel-coding methods in simulations. Molecular Phylogenetics and Evolution, 44, 724-740.

Soltis, D.E., Morris, A.B., McLachlan, J.S., Manos, P.S. \& Soltis, P.S. (2006) Comparative phylogeography of unglaciated eastern North America. Molecular Ecology, 15, 42614293.

Stebbins, G.L. (1974) Flowering plants: evolution above the species level. Belknap Press, Cambridge, MA.

Stewart, J.R. \& Lister, A.M. (2001) Cryptic northern refugia and the origins of the modern biota. Trends in Ecology and Evolution, 16, 608-613.

Stewart, J.R., Lister, A.M., Barnes, I. \& Dalén, L. (2010) Refugia revisited: individualistic responses of species in space and time. Proceedings of the Royal Society B: Biological Sciences, 277, 661-671.

Symonds, V.V., Soltis, P.S. \& Soltis, D.E. (2010) Dynamics of polyploid formation in Tragopogon (Asteraceae): recurrent formation, gene flow, and population structure. Evolution, 64, 1984-2003.

Taberlet, P., Fumagalli, L., Wust-Saucy, A.G. \& Cosson, J.F. (1998) Comparative phylogeography and postglacial colonization routes in Europe. Molecular Ecology, 7, 453-464.
Tajima, F. (1989) Statistical method for testing the neutral mutation hypothesis by DNA polymorphism. Genetics, 123, 585-595.

Williams, J.W., Webb, T., III, Richard, P.H. \& Newby, P. (2000) Late Quaternary biomes of Canada and the eastern United States. Journal of Biogeography, 27, 585-607.

Wróblewska, A. (2012) The role of disjunction and postglacial population expansion on phylogeographical history and genetic diversity of the circumboreal plant Chamaedaphne calyculata. Biological Journal of the Linnean Society, 105, 761-775.

\section{SUPPORTING INFORMATION}

Additional Supporting Information may be found in the online version of this article:

Appendix S1 Voucher and sampling information for Solidago subsect. Humiles populations used in this study.

Appendix S2 Species- and population-level haplotype distributions within Solidago subsect. Humiles.

Appendix S3 Fixation indices and number of singleton populations (Table S1) and geographical groupings from SAMOVA (Fig. S1).

\section{BIOSKETCHES}

Jess A. Peirson is a post-doctoral research fellow in the Department of Ecology and Evolutionary Biology at The University of Michigan. He is interested in the Holocene biogeography and evolution of the North American flora and the evolution and systematics of goldenrods (Solidago, Asteraceae) and spurges (Euphorbia, Euphorbiaceae).

Christopher W. Dick is an associate professor in the Department of Ecology and Evolutionary Biology at The University of Michigan. He is broadly interested in plant ecology and evolution, and has a longstanding interest in the biogeographical history of Neotropical forests.

Anton A. Reznicek is Curator of Vascular Plants at the University of Michigan Herbarium. His primary interests are in the systematics and evolution of sedges (especially Carex, Cyperaceae) and the biogeography, floristics, systematics and conservation of the Great Lakes Region flora.

Editor: Miles Silman 